\title{
A study on deforestation in hilly areas of Haryana using Remote Sensing and GIS technique
}

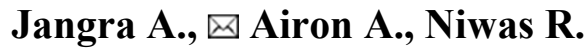

Received: 19.12.2019

Revised: 10.02.2020

Accepted: 08.09.2020

\begin{abstract}
Forest is an essential part or backbone of the earth ecological system. In a country like India, the people and the economy of nation is mainly relies on the diversity of natural resources. In today's world degradation of forest resources is a prime concern for many of the scientists and environmentalists because the canvas had been transformed from last few decades to cultivated and non-cultivated land. In India, Haryana state has lowest forest cover i.e. 3.59\% followed by Punjab 3.65\%. Over the several decades, the advancement of Remote Sensing and Geographical Information System (GIS) technique has emerged as an efficient tool to monitor and analyse deforestation rate in hilly areaor over a variety of location. Remote sensing based vegetation indices show better sensitivity than individual band reflectance and hence are more preferred for assessment and monitoring of tress. The aim of the present study was to analyse the deforestation in hilly areas in Haryana State (India) by remote sensing data with a special focus on Panchkula and Yamunanagar. The information was collected through the LANDSAT 8 satellite of NASA. The result revealed that the deforestation rate is high in Hilly areas of Haryana. The study shows that the forest cover in hilly areas of Haryana in 2013 was $50,879.07$ hectares and in 2019 it was 44,445.51 hectares of land. Thereby decrease in forest cover of $6,433.56$ hectares had been observed in the study period of 2013-2019 i.e. 6 years. Spatial variations in deforestation were also mapped in GIS for the hilly areas in Panchkula and Yamunanagar districts of Haryana.
\end{abstract}

Key Words: Deforestation, Forest resources, Geographical Information System (GIS), Landsat, Remote Sensing

\section{Introduction}

"Water is the essence of Earth, plants are the essence of waters"-Darwin

India has $21.54 \%$ of land under forest cover as opposed to $33 \%$ recommended in the National Forest Policy, according to the report of Forest Survey of India. While Haryana tops the list from below with just $3.59 \%$ forest cover. Every five years, the size of forest cover of Haryana vanishes, leaving behind constantly eroding soil that can hold neither water nor nutrients. Haryana is engaged in a race against time. Within the last decade- thanks to the efforts of reckless deforestation which has pummeled and pulverized the earth into millions of hectares of waste land- there has developed a discernible desert. At stake is the very survival and continuity of the country's agricultural livelihood (Krishna et al., 2015).

Study Area: Hilly ares of Panchkula and Yamunanagar

Haryana came into existence on 1 November 1966. Author's Address

Dept. of Agricultural Meteorology, CCS Haryana Agricultural University, Hisar-125004

E-mail.: jangra.aj.050695@gmail.com
Haryana is a landlocked state bordered by Uttar Pradesh and Uttarakhand in East, Rajasthan in the South, Punjab in the West and Himachal Pradesh in North, in Northern India. It is between $27^{\circ} 39^{\prime}$ to $30^{\circ} 35^{\prime} \mathrm{N}$ latitude and between $74^{\circ} 28^{\prime}$ and $77^{\circ} 36^{\prime} \mathrm{E}$ longitude. The total geographical area of the state is $4.42 \mathrm{~m}$ ha, which is $1.4 \%$ of the geographical area of the country. The altitude of Haryana varies between 700 and $3600 \mathrm{ft}$ (200 metres to 1200 metres) above sea level. Haryana has only $3.59 \%$ (compared to national 21.54\%) area under forests. The district wise forest cover is mentioned in table 1. Karoh Peak, a 1,467 -metre $(4,813 \mathrm{ft})$ tall mountain peak in the Shivalik Hills range of the greater Himalayas range located near Morni hills area of Panchkula district, is highest point in Haryana. Forest cover is analysed in hilly areas of Haryana special focus on Panchkula and Yamunanagar by GIS. The study area is shown in figure1 by green colour. As per the report of Forest Survey of India, Haryana has only $3.59 \%$ of geographical area under forest cover which stands first in whole country from below followed by Punjab (3.65\%). 
Table 1. Showing District wise forest cover.

\begin{tabular}{|c|c|c|c|c|c|c|c|c|}
\hline \multirow[t]{2}{*}{ District } & \multirow{2}{*}{$\begin{array}{l}\text { Geographical } \\
\text { Area }\end{array}$} & \multicolumn{4}{|c|}{2017 Assessment } & \multirow{2}{*}{$\begin{array}{l}\text { \% of } \\
\text { GA }\end{array}$} & \multirow[t]{2}{*}{ Change } & \multirow[t]{2}{*}{ Scrub } \\
\hline & & $\begin{array}{l}\text { Very } \\
\text { Dense } \\
\text { Forest } \\
\end{array}$ & $\begin{array}{l}\text { Moderate } \\
\text { Dense } \\
\text { Forest } \\
\end{array}$ & $\begin{array}{l}\text { Open } \\
\text { Forest }\end{array}$ & Total & & & \\
\hline Ambala & 1574 & 0 & 18 & 34 & 52 & 3.30 & 0 & 1 \\
\hline Bhiwani & 4778 & 0 & 8 & 104 & 112 & 2.34 & 0 & 11 \\
\hline Faridabad & 741 & 0 & 26 & 54 & 80 & 10.80 & 5 & 17 \\
\hline Fatehabad & 2538 & 0 & 3 & 15 & 18 & 0.71 & 1 & 0 \\
\hline Gurgaon & 1258 & 0 & 34 & 83 & 117 & 9.30 & 1 & 17 \\
\hline Hisar & 3983 & 0 & 12 & 45 & 57 & 1.43 & 3 & 4 \\
\hline Jhajjar & 1834 & 0 & 0 & 24 & 24 & 1.31 & 0 & 4 \\
\hline Jind & 2702 & 0 & 5 & 16 & 21 & 0.78 & 0 & 0 \\
\hline Kaithal & 2317 & 0 & 24 & 33 & 57 & 2.46 & 0 & 0 \\
\hline Karnal & 2520 & 0 & 4 & 28 & 32 & 1.27 & -2 & 1 \\
\hline Kurukshetra & 1530 & 0 & 18 & 21 & 39 & 2.55 & -2 & 1 \\
\hline Mahendragarh & 1899 & 0 & 22 & 77 & 99 & 5.21 & -1 & 34 \\
\hline Mewat & 1507 & 0 & 14 & 96 & 110 & 7.30 & 2 & 26 \\
\hline Palwal & 1359 & 0 & 2 & 12 & 14 & 1.03 & -1 & 0 \\
\hline Panchkula & 898 & 6 & 151 & 234 & 391 & 43.54 & -1 & 24 \\
\hline Panipat & 1268 & 0 & 3 & 13 & 16 & 1.26 & 0 & 1 \\
\hline Rewari & 1594 & 0 & 10 & 49 & 59 & 3.70 & 0 & 11 \\
\hline Rohtak & 1745 & 0 & 3 & 16 & 19 & 1.09 & 0 & 0 \\
\hline Sirsa & 4277 & 0 & 3 & 54 & 57 & 1.33 & 2 & 0 \\
\hline Sonipat & 2122 & 0 & 3 & 17 & 20 & 0.94 & 0 & 1 \\
\hline Yamunanagr & 1768 & 22 & 89 & 83 & 194 & 10.97 & 1 & 1 \\
\hline Total & 44212 & 28 & 452 & 1108 & 1588 & 3.59 & 8 & 154 \\
\hline
\end{tabular}

Source: Report of Forest Survey of India, 2017

The study region is situated between parallel of latitude $30^{\circ} 19^{\prime} \mathrm{N}$ to $30^{\circ} 54^{\prime} \mathrm{N}$ and $76^{\circ} 35^{\prime} \mathrm{E}$ to $77^{\circ} 35^{\prime} \mathrm{E}$ longitude as shown in figure 2 .

\section{Objectives of the study}

The primary aim of the study was to analyse the deforestation rate in Hilly areas of Panchkula and Yamunanagar. In addressing this aim, the study focused on the following objectives:

* To assess the distribution of Forest Resources.

* To study the changes in forest cover in hilly areas of Haryana during the period of 2013 and 2019.

\section{Research questions}

This study is conducted for seeking the answer of following questions:

* How the Forest resources are distributed over the study area?
* What are changes observed in deforestation rate in study area during the year 2013 and 2019 ?

\section{Remote Sensing and GIS}

Remote sensing can significantly contribute to providing a timely and accurate picture of deforestation, and it is very suitable gathering information over the large areas with a high revisit frequency with a regional to global scale. The data recorded by current sensor satellites can be used to assess two component of the crop production, yield, and acreage, in addition crop phonological information, stress situation and distribution can be detect.Amongst other thing, the retrieved information permits decision maker to better anticipate of the effects events and get objective and unbiased spatial picture over large area rick management. Geographic Information System (GIS) have emerged as a powerful tool in the management and analysis of the large amount of spatial-temporal data and information, and also to generate information products in the form of maps 
A study on deforestation in hilly areas of Haryana

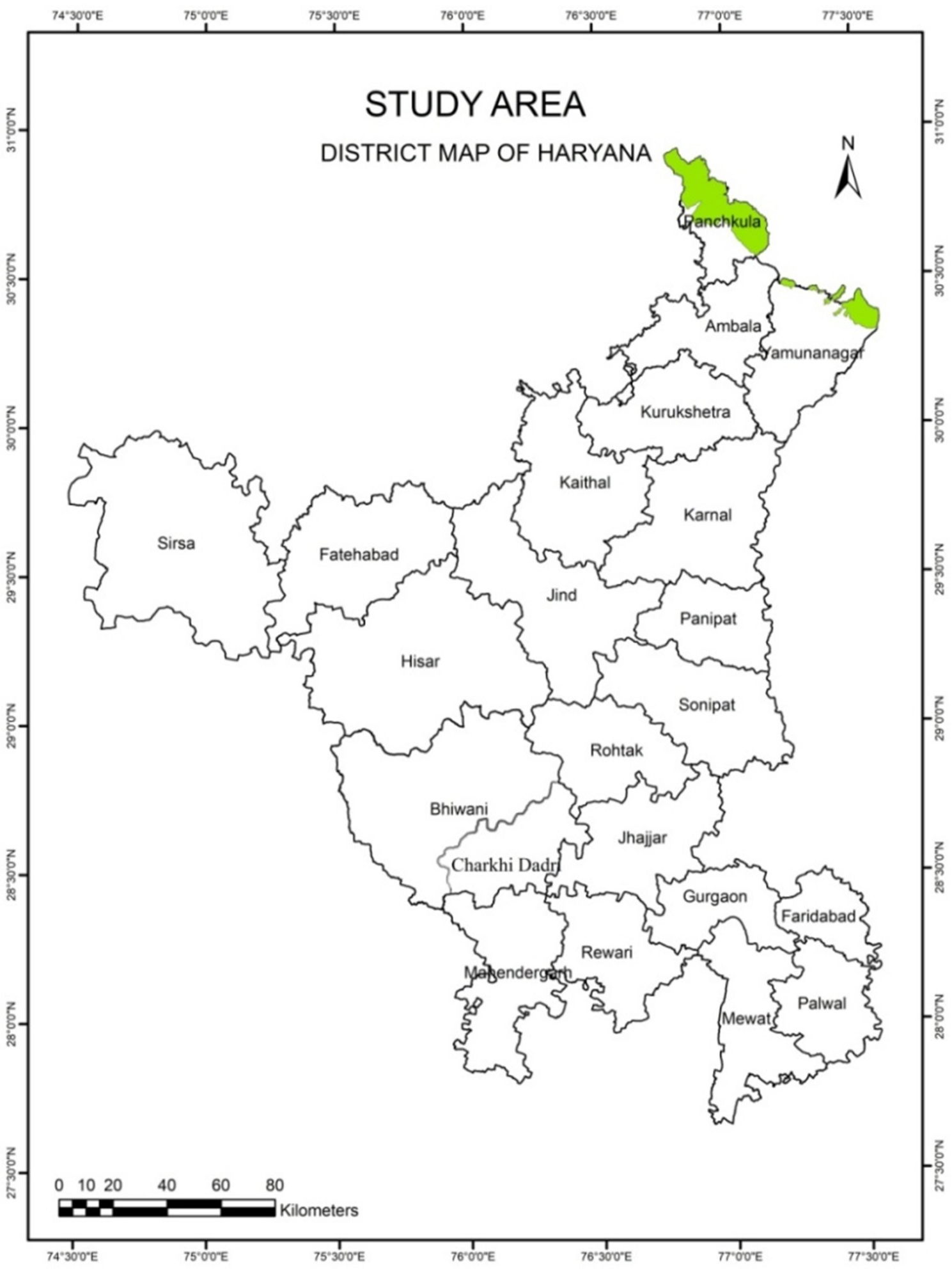

Fig 1. District map of Haryana representing study area. 


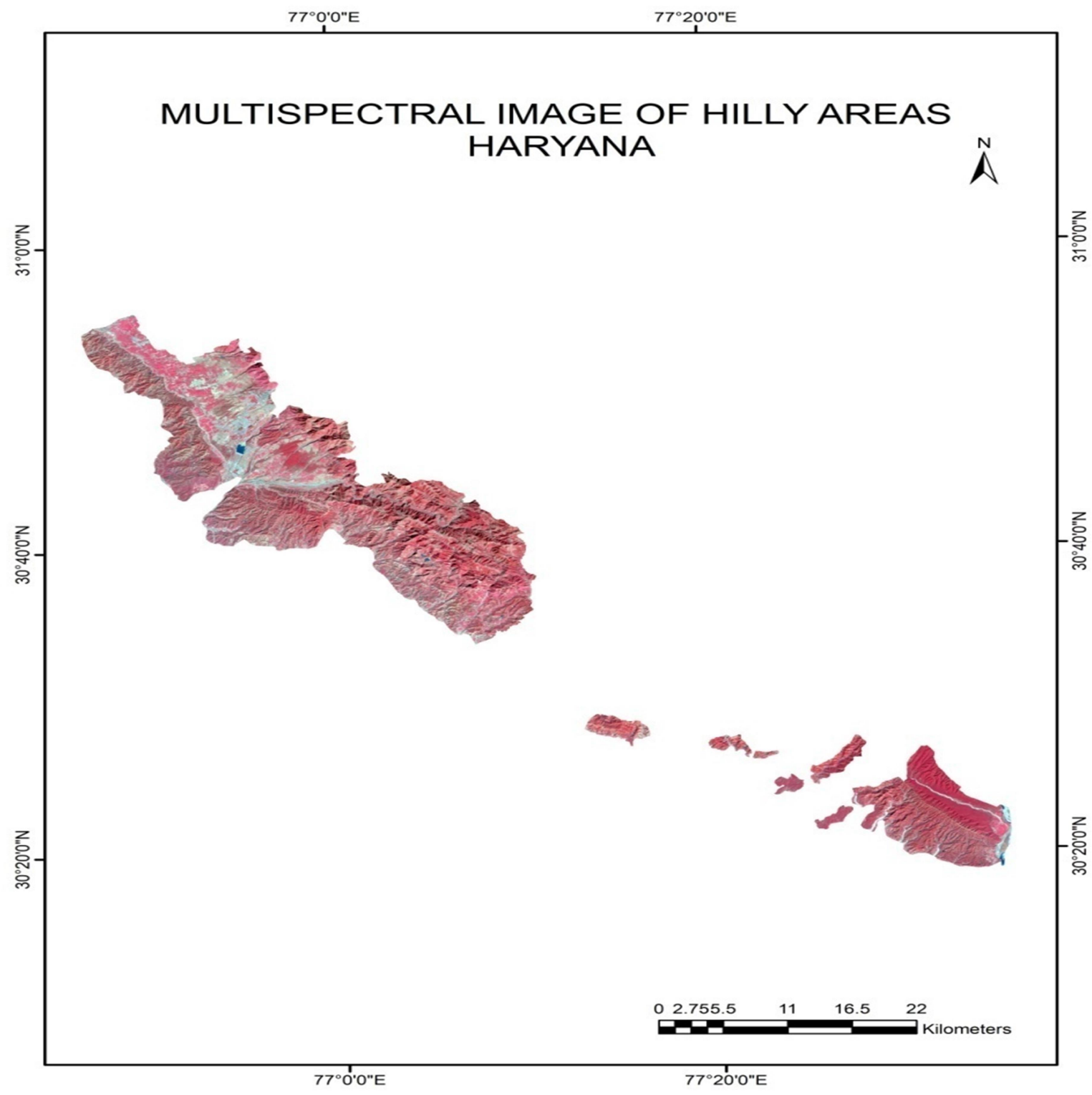

Fig 2. Multispectral image of hilly areas of Panchkula and Yamunangar.

as well as tabular and textual reports for land use decisions. In recent years FAO has been developing GIS in linkage with its agro-ecological zoning and similar models, applying these to tackle issues of deforestation at regional levels. Now a days, at large (local) as well as small scale (regional/national) there has been remarkable progress in developing GIS-based tools/packages for identifying the areas which are most affected due to deforestation. The present study summarizes the Remote Sensing application in area affected due to deforestation in the Haryana state.

\section{Methodology}

The Landsat 8 data (free source) scene acquired from Landsat site was used for analysis. Landsat 8 Operational Land Imager (OLI) and TIRS (Thermal Infrared Sensor) image consist of eleven spectral bands with a spatial resolution of 30 meters for Bands 1 to 7 and 9 to11. The resolution for Band 8 (panchromatic) is 15 meters. The wavelength and resolution of each band is shown in table 2. Landsat 8 records data in different bandwidths. 
Table 2. Showing Landsat Bands.

\begin{tabular}{|l|l|l|l|}
\hline $\begin{array}{l}\text { Landsat 8 } \begin{array}{l}\text { Operational } \\
\text { Land Imager } \\
\text { (OLI) and }\end{array} \\
\text { Thermal }\end{array}$ & Bands & $\begin{array}{l}\text { Wavelength } \\
\text { (micrometers) }\end{array}$ & $\begin{array}{l}\text { Resolution } \\
\text { (meters) }\end{array}$ \\
\cline { 2 - 4 } $\begin{array}{l}\text { Infrared } \\
\text { Sensor } \\
\text { (TIRS) }\end{array}$ & Band 1- Ultra Blue & $0.435-0.451$ & 30 \\
\cline { 2 - 4 } & Band 2- Blue & $0.452-0.512$ & 30 \\
\cline { 2 - 4 } & Band 3- Green & $0.533-0.590$ & 30 \\
\cline { 2 - 4 } & Band 4- Red & $0.636-0.673$ & 30 \\
\cline { 2 - 4 } & Band 5- Near Infrared & $0.851-0.879$ & 30 \\
\cline { 2 - 4 } & Band 6- Shortwave Infrared (SWIR) 1 & $1.566-1.651$ & 30 \\
\cline { 2 - 4 } & Band 7- Shortwave Infrared (SWIR) 2 & $2.107-2.294$ & 15 \\
\cline { 2 - 4 } & Band 8- Panchromatic & $0.503-0.676$ & 30 \\
\cline { 2 - 4 } & Band 9- Cirrus & $1.363-1.3824$ & $100 *(30)$ \\
\cline { 2 - 4 } & Band 10_-Thermal Infrared (TIRS) 1 & $10.60-11.19$ & $100 *(30)$ \\
\cline { 2 - 4 } & Band 11- Thermal Infrared (TIRS) 2 & $1.50-12.51$ & 30 \\
\hline
\end{tabular}

Step 1

\section{Data Acauisition}

Importing data from compressed Landsat 8 scene

Step 2

Geo-referencing Data

(Evaluation with available maps and images)

Step 3

Classification of imageries

Unsupervised classification

Identifying classes and cross check with ground truth samples

Step 4

Preparing of Mosaics

Mosaics of different scenes and clipping with state boundary

Interpretations

Interpreting the results

Fig 3. Showing flow chart of methodology.

$$
73
$$

Environment Conservation Journal 
These bandwidths are broken down into portions of the visible, NIR and SWIR infrared regions of the electromagnetic spectrum. From these various bandwidths, a great deal of information about the land cover can be displayed and analyzed. In the present research, Digital image analysis was carry out in Erdas imagine and Arcgis software, the Geotiff data was import to Erdas imagine format GIS Lab of Department of Agricultural Meteorology, CCS HAU Hisar. Hilly areas of Haryana state falls under 147 path 39 row. Best cloud-free Landsat were selected for analysis and study area extracted. Landsat operates in multispectral bands. These multispectral regions can bring more information that can differentiate in cops. The SWIR is particularly significant in the vegetation canopy cover. The unsupervised classification for single date data was carried out

Time period of scene required for rate of deforestation analysis is $14^{\text {th }}$ December 2013 and $29^{\text {th }}$ January 2019. Step by step methodology starting from importing of data to classification is presented through figure 3 .

\section{Results and Discussion}

In a multispectral image, each pixel has a spectral signature determined by theReflectance of that pixel in each of the spectral bands. Multispectral classification is an information extraction process that analyzes the spectral signatures and then assigns pixels to classes based on similar signatures (Sabin, 2007). For example, all of the pixels which represent an area of forested land on a TM image should have roughly the same spectral signature. Classification procedures attempt to group together such similar pixels (Lapworth et al., 2014).

This way, a layer can be generated with each land cover type represented by a different class. The detail of the classes depends on the spectral and spatial resolution characteristics of the imaging system. Landsat imagery is usually good for creating a general land cover classification map. Unsupervised classification is a method in which the computer searches for natural groupings of similar pixels called clusters (Lapworth et al., 2015).

In ERDAS unsupervised classification is performed using an algorithm called the Iterative SelfOrganizing Data Analysis Technique (ISODATA).
Using this algorithm, the analyst input the number of clusters desired and a confidence threshold. The computer or software, then build clusters iteratively, meaning that with each new iteration, the clusters become more and more refined (Rodell et al., 2009). The iterations stop when the confidence level (or a maximum number of iterations specified by the user) is reached. For example, if the user wants 30 clusters at $95 \%$ confidence, the computer will iteratively build the clusters until it is $95 \%$ confident has attained the best distribution of pixels into 30 clusters (Singh, 1990; Macdonald et al., 2014).

For identifying the classes, each class was highlighted at a time and then determines which of the landuse it belonged to by interpreting the original multispectral image. Fig. 3 shows that landsat scenes used in the study and Fig. 5shows forest cover in 2013. Figure 6 show forest cover in 2019 in Hilly areas of Haryana. In addition to MSS, NDVI of the image was also prepared and compared with each class to identify vegetation. Then each class was given a color such as water as blue. Finally, the image was exported to map as shown below. To get the results for Haryana, an AOI layer was created in ERDAS and final classified image was cropped (subset) for Haryana AOI layers.

\section{Forest cover in 2013}

Remote Sensing techniques are being effectively used in India and aboard for mapping and monitoring forest cover. In the present report, the temporal remote sensing data is used for assessing the extent of depletion of forest cover in the Hilly areas of Haryana. Degradation of forest resources is over exploited for a longer duration in an injudicious manner. There may or may not be direct impact in the beginning, but the continuous misuse may lead to such a situation when it becomes more glaring and may pose a threat to the very survival of mankind. As it stated above that the forest cover in Haryana is $3.59 \%$ of geographical area. The rate of deforestation has increased rapidly as the dependency of population on environmental resources has increased for their sustainability. In 2013 , the area under forest cover is $50,879.07$ hectares of land of Hilly areas of Haryana as shown in figure 4. 


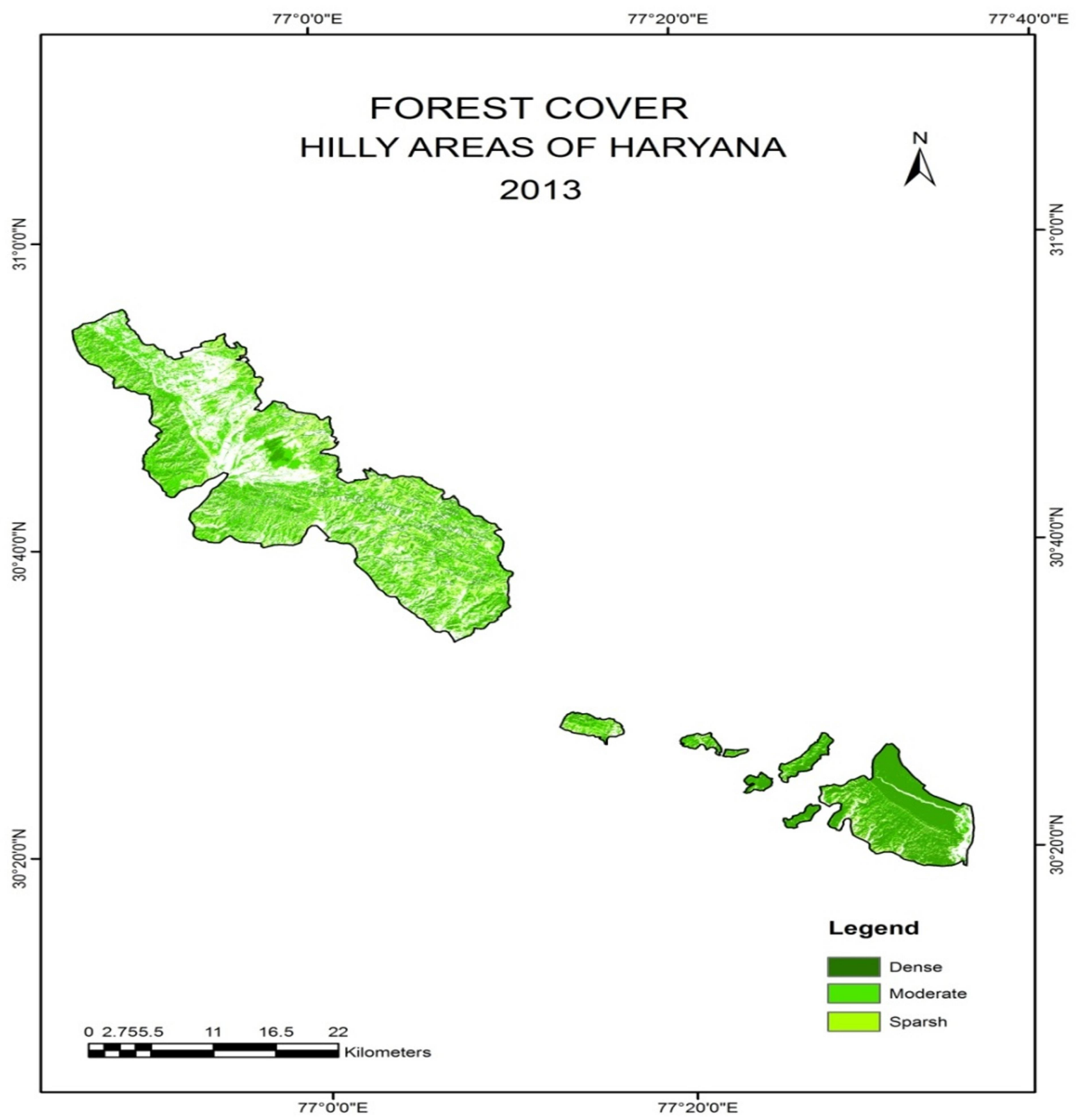

Fig 4. Forest cover in 2013.

\section{Forest cover in 2019}

National Forest Policy, 1952 envisages that a one third of the area in the country should be under forest cover, however, in hilly tract it should be $60 \%$. In the past, vast forest areas have been cut for agricultural purpose. In addition to the supply of timber and fuel wood, the forests are providing leaf fodder for the animals of nomadic people settled in the forest and nearby villages. In the present study, it is noticed that the forest area have been decreased

from 2013 to 2019. As it is stated earlier that, in 2013 the geographical area under forest cover was $50,879.07$ hectares of land but whereas the deforestation rate in 2019 is around 44,445.51 hectares of land shown in figure 5. These images were visually interpreted for studying the changes and a map showing depleted forest areas and changes during these years has been prepared. 


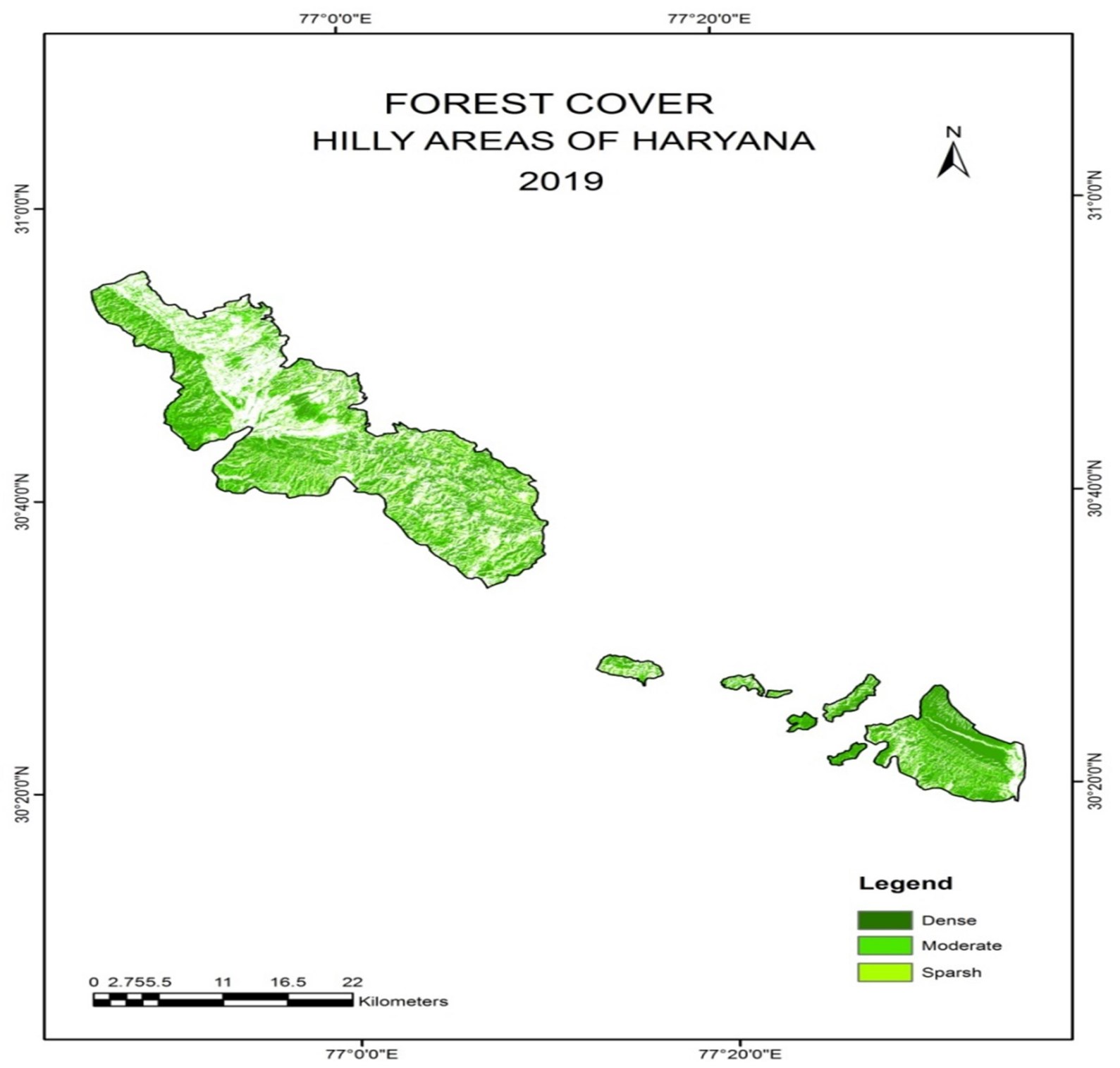

Fig 5. Forest cover in 2019.

\section{Conclusion}

In a developing country like India, deforestation causes lot of chaos and hue in the country. The study provides insight into forest cover in the state of Haryana with specific focus on hilly areas of Panchkula and Yamunanagar. Total of 6,433.56 hectares of forest cover had reduced in the study and in the period under study (2013-2019). The vulnerability of losing forest cover is very high. The hilly areas with densely populated trees are vulnerable from many natural and man-made activities. The decrease in forest area is highly alarming as compared to time period it has taken. The problem of deforestation can be assessed clearly by the decay. Spatially, more depletion in forest cover has observed in North-Western parts from the South-Eastern parts. As per visual interpretation of satellite image it can be said that forest cleaned area was shifted to agricultural land use. More concern are required to maintain forest cover is the zone as it is the only forest resource of state. 


\section{References}

Krishna, G., Singh, R. P., Khanna, A., Singh, S. and Ghosh, N. C. 2015. Recent Forest status of Forestcover in Haridwar district, Uttarakhand. In:Proceedings of National Seminar on $R \& D$ Perspective for Rejuvenation of River Ganga during 16-17 December, at NIH, Roorkee, pp:12-13.

Lapworth, D. J., Krishna, G., Macdonald, A. M., Rao M. S., Goody, D. C., et al. 2015. Forest profile of intensively exploited resources in northwest India. Geophysical Resources in northwest India. Geophysical Research letters., 42: 7554-7562.

Lapworth, D. J., Krishna, G., Rao, M. S. and MacDonald, A. M. 2014. Intensive Deforestation Exploitation in the Punjab - an Evaluation of Resource and quality Trends. Technical Report. NERC Open Research Archive pp:34.
Macdonald, A. M., Bonsor, H. C., Krishna, G., Rao M. S. and Ahmed, K. M., et al. 2014. Forest cover in the Indogangetic Basin: Evolution of Groundwater Typologies. In: Proceeding of 41stInternational Assocation of Hydrogeologist (IAH-2014) on Forest cover: Challenges and Strategies.

Rodell, M., Velicogna, I. and Famiglietti, J. S. 2009. Satellitebased estimates of Forest cover depletion in India. Nature, 460: 999-1002.

Sabin, F. 2007. Remote Sensing: Principles and Applications, Third Edition Waveland, Press ISBN 1478610085

Singh, A. 1990. Digital change detection techniques using remotely-sensed data 1989. Int. J. Remote Sensing, 10(6): 989-100. 